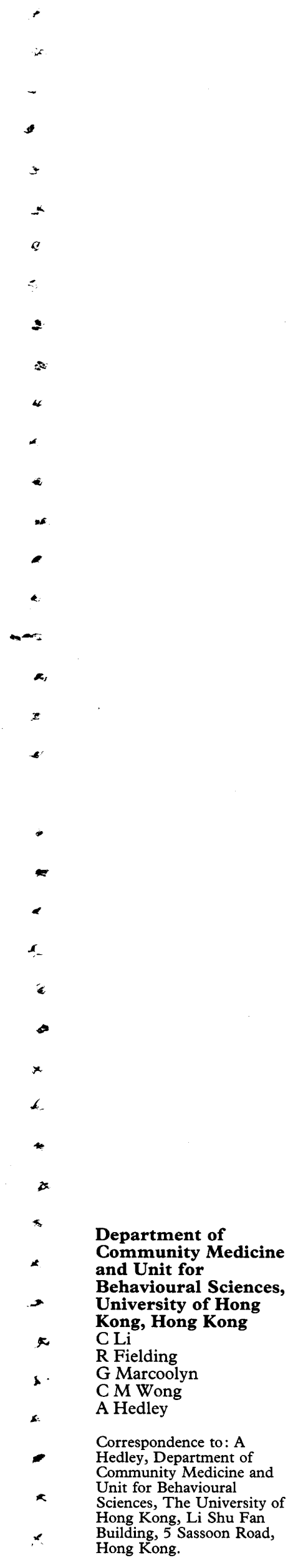

\title{
Smoking behaviour among female airline cabin crew from ten Asian countries
}

\author{
Cecilia Li, Richard Fielding, Gillian Marcoolyn, Chit Ming Wong, Anthony Hedley
}

\begin{abstract}
Objective - To identify factors related to the high prevalence of smoking behaviour among a sample of female airline cabin crew of Asian origin.

Design-A questionnaire-based crosssectional survey of 585 Asian women, aged 20-41 years working as experienced cabin crew for a major international airline.

Main outcome measures-Subjects answered questions on their knowledge of the consequences of smoking, the perceived effects of smoking, their perceptions of the social images of smoking and non-smoking women, and current and past smoking behaviour. Subjects also rated women depicted in cigarette, cosmetic, alcohol and luxury goods advertisements using ten predefined social descriptors.
\end{abstract}

Results-An overall current smoking prevalence of $26 \%$ (95\% confidence interval $22-30 \%$ ) was identified, with wide variation according to national origin of subjects. More than $75 \%$ of respondents were aware of the commonly emphasized hazards of smoking, and no significant differences were found in health knowledge between smokers and non-smokers. However, only about half of the subjects correctly identified the interactions between smoking and oral contraceptive use and the increased risk for heavy smokers of dying before the age of 65 years. More smokers than non-smokers believed cigarettes could help control body weight. Smokers emphasized positive effects of smoking more than nonsmokers, and smokers tended to perceive women depicted in cigarette advertisements as attractive, elegant, fit, sociable, and adventurous to a greater degree than did non-smokers.

Conclusions - There was no difference in health knowledge about tobacco-related diseases between smokers and nonsmokers. It seems, therefore, that health risks alone are not reason enough for smokers to change smoking behaviour in this study population. Instead, health promotion should emphasize the social detriment of smoking for women, and restrictions on the depiction of positive social images in tobacco advertising should be considered.

(Tobacco Control 1994; 3 : 21-29)

\section{Introduction}

Current female smoking prevalence rates in industrialised countries are approaching those of males, as is the amount smoked by females. Efforts to prevent smoking in these countries have contributed to reductions in smoking rates that are more rapid among males than among females. ${ }^{1}$ Women are also taking up smoking at younger ages. ${ }^{1,2}$

Conversely, smoking rates in Asia are increasing. Potential market expansion makes Asia the key target for the tobacco industry. Among Asian women, the prevalence of smoking is increasing. With some specific exceptions, smoking prevalence rates among females in Asia range from 3 to $14 \%$ (figure 1) and generally remain lower than those of western countries where female smoking rates are generally about $30 \% .^{3}$

Among Asian countries, Japan currently has the highest female smoking rate $(14 \%)$, while Hong Kong has the lowest (3\%) (figure 1). In Hong Kong, however, these summary statistics conceal higher smoking rates and important trends in some groups. Age-specific prevalence rates for female smokers in Hong Kong reveal that smoking rates among the younger age groups have increased over the past 10 years. The population age-specific prevalence rate of smoking among the 15- to 19-year-old group has increased from $0.4 \%$ to $1.1 \%$, and among the 20 - to 29 -year-old group from $1.5 \%$ to $2.0 \%$ between $1982-1990$ (figure 2 ). ${ }^{4}$ Similarly, in Taiwan, the prevalence of female smokers almost doubled from $7.0 \%$ to $13.4 \%$ during a 12-month period from 1989-1990, where women aged 15-17 years have the second highest smoking rates after women aged over 61 years. ${ }^{5}$ In Hong Kong a recent study of female primary school children aged 8-11 years found ever-smoking prevalence ranged from $3.3 \%$ (primary 3 ) to $6.9 \%$ (primary 4).

If this trend is not controlled, prevalence rates among young Asian females may soon rival those in developed countries.

The principal aim of this study was to identify reasons for the uptake, maintenance, and cessation of smoking among a group of young professional Asian women from nine countries: Korea, Thailand, Philippines, Malaysia, Singapore, Japan, Indonesia, India, Taiwan, and the territory of Hong Kong; and ultimately to use these data to design strategies to combat the increase in smoking. 


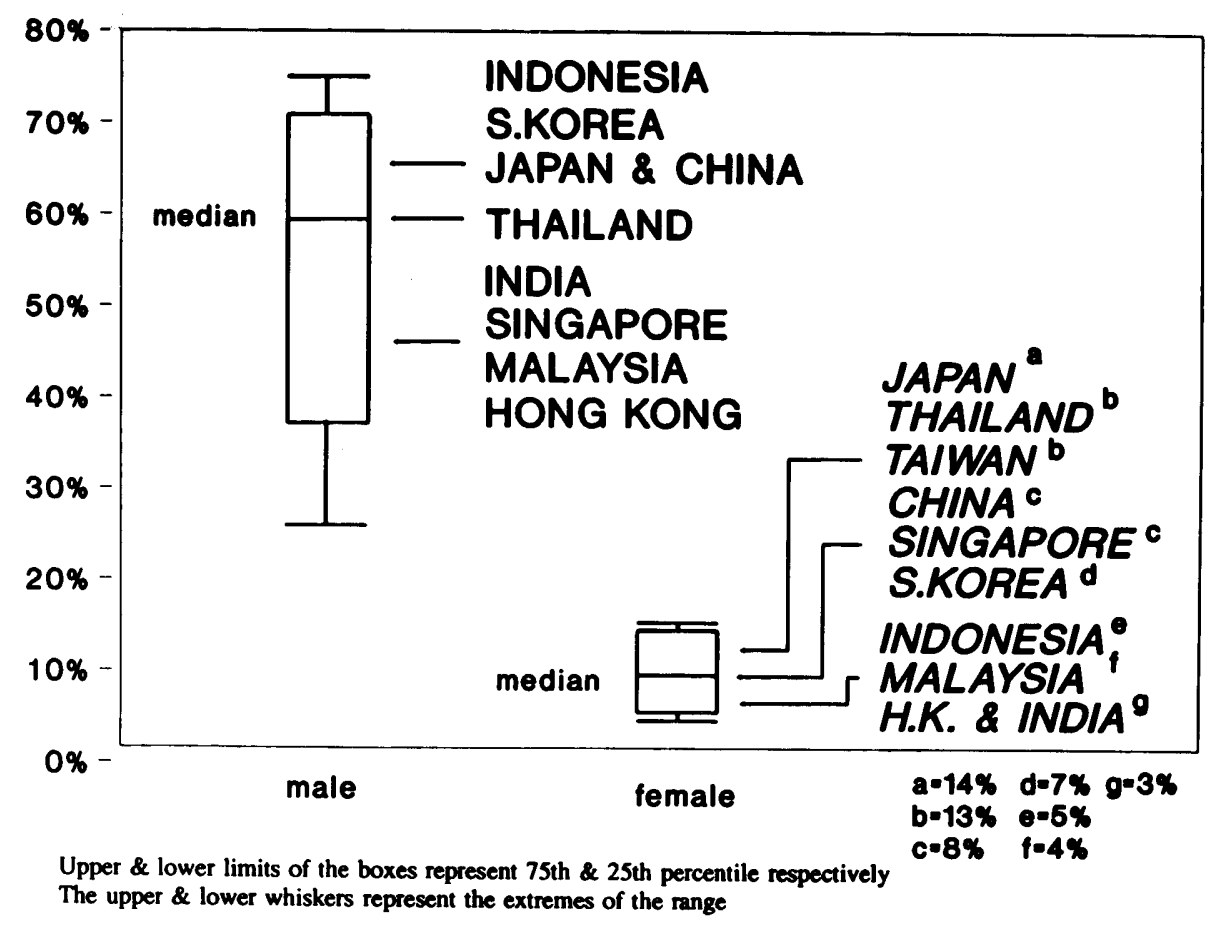

Figure 1 Quartile distribution for female smoking prevalence in Asia

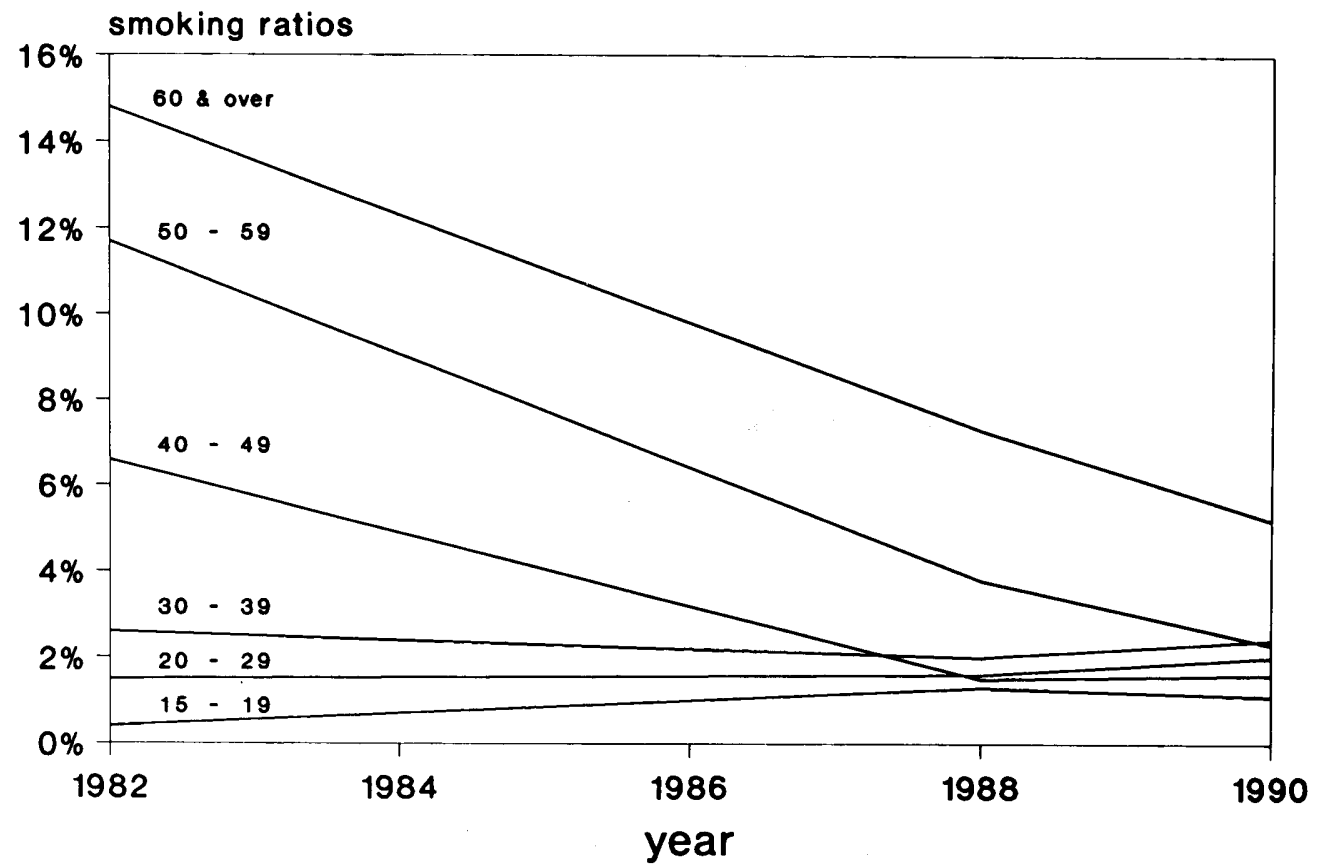

Figure 2 Female smoking prevalence in Hong Kong. Age-specific ratios in the years 1982, '88 and '90

\section{Methods}

BACKGROUND

Estimated smoking rates in the region of $25 \%$ among female cabin crew prompted the principal medical officer of a major airline to approach us to carry out a series of surveys from April 1990 onwards to confirm and study the possible reasons for this high smoking prevalence.

\section{SUBJECTS}

Subjects comprised female cabin crew attending courses at the staff training centre of an international airline from April to September
1990. A total of 585 experienced crew attending refresher courses were recruited representing a response rate of $91.5 \%$.

The working environment of the crew includes both regional and intercontinental flights on wide-bodied jets. All of the crew in the study had duties related to passenger hospitality and flight safety. Crew are allocated on an individual basis to an average of $60-70$ flight hours in a month, with periods of nine days off per month.

Subjects completed a self-administered ques- 
tionnaire and took part in a brief group presentation. The instrument was designed to assess: 1) their knowledge about the consequences of smoking, 2) the perceived effects of smoking, 3) the subject's perception of social images of smoking and non-smoking women, and 4) personal characteristics and smoking behaviour.

English is not the first language of most of the cabin crew; therefore, to minimise error from differences in comprehension of the questionnaire, three steps were taken. First, the questionnaire was worded in very simple english. Second, a researcher was available to explain queries at most of the data collection sessions. Third, clear definitions of the ten characteristics that were used to assess the social images of smoking and non-smoking women were given to avoid misunderstandings. Although these measures may not exclude comprehension errors completely, few queries were raised about the meaning of the questionnaire items.

A number of pre-tests of the draft instrument were carried out with small samples. A formal pilot study was then carried out on a sample of 50 crew at the airline training centre, following which the survey instrument was refined and the method of presentation modified accordingly.

\section{BELIEFS ABOUT HEALTH RISKS}

Ten questions assessed beliefs about the health consequences of smoking. Each question was answered on a five-point Likert scale ranging from strongly agree to strongly disagree. To avoid acquiescence response set, five questions were phrased negatively. All were phrased in such a way that agreement reflected accurate belief; responses in agreement scored 1 ; and all neutral and missing items scored 0 . A composite knowledge score was obtained for each respondent by summing the total number of correct items. The range of possible scores was 0 to 10 . Higher composite knowledge scores represent more accurate respondent knowledge of the health consequences of smoking.

\section{PERCEIVED COSTS AND BENEFITS OF SMOKING}

Respondents were provided with a list of 14 consequences of smoking. Half of these were positive consequences and half were negative. Respondents were asked to choose their expectations of the consequences of smoking from this list. For each consequence, respondents were then asked to rate, on a scale ranging from $0 \%$ to $100 \%$, their perceived probability of these consequences occurring if they smoked cigarettes daily.

\section{SOCIAL IMAGES OF SMOKING}

The frequent use of social images by tobacco companies in advertising suggests that they exert a powerful influence on smoking behaviour. In an attempt to assess the social images of smoking women, and after careful consideration of the women portrayed in tobacco advertisements, we selected seven characteristics. These were: feminine, attractive, elegant, fit, sociable, adventurous, and liberated. These terms were selected as having neutral to positive social desirability. As the women in tobacco advertisements are invariably depicted as having socially desirable characteristics designed to appeal (presumably) to women and girls, it was necessary to generate a number of less desirable characteristics to avoid biasing responses too much in a positive direction, so three terms considered to be neutral to negative were included. These were impulsive (neutral), lacking in confidence (negative), and unsophisticated (neutral/ negative). Using these characteristics, respondents were asked to decide if each applied most to either smoking women, non-smoking women, or all women. Only one choice was allowed for each characteristic. Interpretations of the meanings of these terms are dependent on differences in individual understanding. To minimise variation in differences in English language comprehension between different nationalities, the definitions of these characteristics accompanied the questionnaire.

These ten characteristics were also used to describe women shown in six common advertisements, three of which were for tobacco and three for either alcohol or luxury goods. Each tobacco advertisement was matched with a non-tobacco advertisement based on: 1) the setting of the advertisement, 2) the number of persons depicted, and 3) the type of activity shown in the ad. Three pairs of advertisements were formed. The first pair included an alcohol advertisement paired with Kent; the second pair a cosmetic advertisement paired with Virginia Slims; and the third pair a watch advertisement paired with Salem. Each tobacco advertisement was shown after the nontobacco advertisement. The subjects were given two minutes to classify the women depicted in each advertisement on the list of ten terms described above.

\section{PERSONAL CHARACTERISTICS AND SMOKING BEHAVIOUR}

Finally, respondents were asked about their personal characteristics and smoking behaviour, including age of starting smoking, reasons for starting or stopping smoking, and number of cigarettes smoked per day.

Respondents were asked to select one of five categories on the basis of their smoking status. These were: (a) regular smoker (smokes daily or at least once a week), (b) occasional smoker (smokes less than once a week), (c) ex-smoker (smoked in the past but has stopped smoking for at least one month), (d) trier (has tried smoking once or a few times only), and (e) nonsmoker (never smoked).

\section{DATA COLLECTION}

The techniques used to elicit and collect data were a self-administered questionnaire and a slide show of the six advertisements. There 
were two groups of experienced cabin crew, one undergoing safety training, and the other pre-promotion training. Time constraints led to two slightly different methods of data collection. These methods were: 1) classroom interview and questionnaire completion, and 2) a combined method (classroom interview with slide presentation for rating of advertisements and a take-home questionnaire). Data were collected at the airline training centre. However, despite reassurance given about confidentiality, some respondents, unsure of their employer's role in the study, were unwilling to tell us their smoking status. And some did not report their smoking status accurately. This was discovered by talking informally to a selection of cabin crew after the interview. The prevalence of smoking among cabin crew may be under-reported by about $10 \%$. The effect of this will be to minimise rather than enhance any differences identified between smokers and non-smokers in the results.

\section{ANALYSIS}

The proportions of responses for each category were calculated for questions in each section. The original five smoking status categories were collapsed into three categories: 1) current smokers (including regular and occasional smokers), 2) ex-smokers, and 3) never-smokers (including triers and "non-smokers"). Means and standard deviations were calculated for group data. Chi-square values were calculated for goodness of fit and linear trend for the distribution of responses for these three groups. Associations between smoking groups and their perceptions of costs and benefits are indicated by odds ratios (ORs) using either current smokers or never-smokers as the reference $(O R=1$ indicates the reference group). OR for categorical data were cast into a $2 \times 2$ table, the OR being $=\mathrm{ad} / \mathrm{bc}$, where a, $b, c$, and $d$ are the cell counts of the table. All OR calculations used Epi Info version 5.0 (USD Inc, Stone Mountain, Georgia, USA, 1990).

Analysis of variance was used to compare the mean composite knowledge scores and the mean chance of developing adverse health effects of smoking for the three smoking categories of cabin crew. Prevalence rates are expressed as percentages with $95 \%$ confidence intervals (CIs) in parentheses. Simultaneous multiple comparisons between current, ex-, and never-smokers were carried out using the Scheffe test (SPSSPC version 4.0; SPSS Inc, Illinois, 1991).

\section{Results}

\section{RESPONDENTS}

The experienced crew were aged $20-41$ years, with $87 \%$ being less than 30 years old. Twenty-five percent were married, $73 \%$ were single and $2 \%$ were cohabiting, separated or widowed. Sixty-nine percent had been employed by the airline for less than five years, $20 \%$ for $6-10$ years and $11 \%$ for more than 10 years. Seventy-eight percent reported a religious belief, mainly Christian or Buddhist.

Most experienced cabin crew originated from the Philippines ( $22 \%$ ), the Hong Kong Chinese Community (19\%), Malaysia (14\%), Singapore $(14 \%)$, and Thailand $(10 \%)$. Other subjects originated from Japan $(7 \%)$, India $(5 \%)$, Korea $(5 \%)$, Taiwan $(2 \%)$, and Indonesia $(1 \%)$.

\section{PREVALENCE OF SMOKING}

Of the 585 experienced crew, 26\% were current smokers, $11 \%$ ex-smokers, and $63 \%$ never-smokers (table 1). Korean women had the highest rate of ever smoking $(67 \%$; $95 \% \mathrm{CI}=50-84 \%$ ), followed by Philippinos $(42 \% ; 33-51 \%)$ and Thais $(42 \% ; 30-54 \%)$. The smoking prevalence among Hong Kong crew was $24 \%(16-32 \%$ ) (table 2 ).

\section{SMOKING BEHAVIOUR}

The average age at which respondents had started to smoke was 20 years. The most common reasons for starting smoking were: 1 ) an attempt to control mood $(56 \%) 2$ ) curiosity $(47 \%)$, and 3 ) influence of friends $(45 \%)$. Twenty-four percent of ever-smokers smoked more than 10 cigarettes per day, another quarter of the ever-smokers consumed 6-10 cigarettes per day, and half of the ever-smokers smoked less than six cigarettes per day. Seventy-three percent of ever-smokers reported having tried to stop smoking at least once. The remainder were occasional smokers who reported that they smoked too few cigarettes to quit. Ex-smokers were older $(\mathrm{F}=4.45, \mathrm{df}=$ $2.568, \mathrm{p}=0.012$, more likely to be married $\left(\chi^{2}=7.58, \mathrm{df}=2, \mathrm{p}=0.023\right)$, and had fewer smoking friends $\left(\chi^{2}=46.41, \mathrm{df}=4, \mathrm{p}<\right.$ $0.0001)$. Among ex-smokers, $92 \%$ of them named their reasons for stopping smoking;

Table 1 Smoking prevalence among experienced female cabin crew

\begin{tabular}{|c|c|c|}
\hline \multirow[b]{2}{*}{ Smoking status } & \multicolumn{2}{|c|}{ Experienced crew } \\
\hline & $\%$ & $n$ \\
\hline $\begin{array}{l}\text { Current smoker } \\
\text { Ex-smoker } \\
\text { Never-smoker }\end{array}$ & $\begin{array}{l}26 \\
11 \\
63\end{array}$ & $\begin{array}{r}152 \\
62 \\
371\end{array}$ \\
\hline Total & 100 & 585 \\
\hline
\end{tabular}

Table 2 Prevalence of ever-smoking among cabin crew, by nationality

\begin{tabular}{lrrr} 
& & \multicolumn{2}{c}{ Ever-smokers } \\
\cline { 3 - 4 } Prevalence & $n$ & $\%$ & $(95 \% C I)$ \\
\hline Korean & 30 & 67 & $(50-84)$ \\
Thai & 60 & 42 & $(30-54)$ \\
Philippino & 129 & 42 & $(33-51)$ \\
Malaysian & 82 & 38 & $(27-49)$ \\
Singaporean & 84 & 35 & $(25-35)$ \\
Japanese & 38 & 34 & $(19-49)$ \\
Indonesia & 6 & 33 & $(0-71)$ \\
Indian & 30 & 33 & $(16-50)$ \\
Taiwan & 12 & 25 & $(0-50)$ \\
Hong Kong & 113 & 24 & $(16-32)$ \\
Total & $584 \star$ & & \\
\hline
\end{tabular}

* One respondent's nationality unknown. 
Table 3 Beliefs about health consequences of smoking

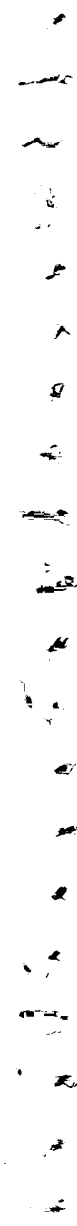

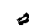$$
\therefore 2
$$$$
\leftarrow
$$$$
\rightarrow
$$$$
+2
$$

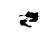$$
+2
$$$$
\therefore
$$

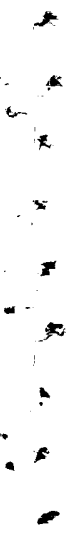

\begin{tabular}{llccc}
\hline & \multicolumn{5}{c}{$\%$ Holding belief } \\
\cline { 2 - 5 } Consequences of smoking & $\begin{array}{c}\text { Current } \\
\text { smokers }\end{array}$ & $\begin{array}{c}\text { Ex- } \\
\text { smokers }\end{array}$ & $\begin{array}{c}\text { Never- } \\
\text { smokers }\end{array}$ & $\begin{array}{c}\text { Total } \\
\text { sample }\end{array}$ \\
\hline Lung cancer & 86 & 85 & 90 & 86 \\
Pregnancy complication & 84 & 74 & 83 & 83 \\
Passive smoking is harmful & 85 & 81 & 79 & 81 \\
Shorten life & 70 & 76 & 78 & 76 \\
Heart disease & 78 & 74 & 75 & 76 \\
Shortness of breath & 79 & 69 & 75 & 75 \\
Filter cigarettes are harmful & 72 & 74 & 69 & 71 \\
Contraceptive interaction & 59 & 58 & 51 & 54 \\
Chance of dying & 38 & 49 & 47 & 45 \\
Helps control body weight & 48 & 29 & 34 & $37 \star$ \\
\hline
\end{tabular}

$\star \chi^{2}=10.22 ; \mathrm{df}=2, \mathrm{p}=0.006$

Table 4 Proportions ( $\%$ ) of ever-smokers and never-smokers perceiving listed costs and benefits of smoking

\begin{tabular}{|c|c|c|c|c|}
\hline & $\begin{array}{c}\text { Current smokers } \\
\%(O R: 95 \% C I)\end{array}$ & $\begin{array}{c}\text { Ex-smokers } \\
\%(O R: 95 \% C I)\end{array}$ & $\begin{array}{c}\text { Never-smokers } \\
\%(O R: 95 \% \text { CI })\end{array}$ & $\begin{array}{c}\chi^{2} \\
\text { (for trend) }\end{array}$ \\
\hline $\begin{array}{l}\text { Benefits } \\
\text { Feeling relaxed } \\
\text { Feeling good } \\
\text { More at home in a group } \\
\text { More attractive } \\
\text { More alert and concentrate better } \\
\text { Less bored } \\
\text { More confident }\end{array}$ & $\begin{array}{l}74(3.9: 4.4-10.9) \\
70(8.7: 5.5-13.8) \\
42(3.0: 1.9-4.6) \\
25(3.4: 1.9-6.0) \\
44(3.6: 2.3-5.7) \\
64(5.2: 3.4-8.1) \\
34(3.0: 1.9-4.9)\end{array}$ & $\begin{array}{l}38(1.5: 0.8-2.7) \\
34(2.0: 1.0-3.7) \\
26(1.5: 0.8-2.9) \\
13(1.6: 0.6-3.8) \\
20(1.1: 0.5-2.4) \\
39(1.9: 1.0-3.4) \\
23(1.8: 0.9-3.6)\end{array}$ & $\begin{array}{r}29(1.0) \\
21(1.0) \\
19(1.0) \\
9(1.0) \\
18(1.0) \\
26(1.0) \\
14(1.0)\end{array}$ & $\begin{array}{r}81.0^{\star \star \star} \\
103.0^{\star \star \star} \\
25.2^{\star \star \star} \\
21.3^{\star \star \star} \\
34.0^{\star \star \star} \\
64.1^{\star \star \star} \\
23.4^{\star \star \star}\end{array}$ \\
\hline $\begin{array}{l}\text { Costs } \\
\text { Have lung cancer } \\
\text { Stain fingers and teeth } \\
\text { Shortness of breath } \\
\text { Die at younger age } \\
\text { Addicted to cigarettes } \\
\text { Have heart disease } \\
\text { Impaired taste and smell }\end{array}$ & $\begin{array}{l}81(1.0) \\
84(1.0) \\
76(1.0) \\
61(1.0) \\
76(1.0) \\
75(1.0) \\
60(1.0)\end{array}$ & $\begin{array}{l}87(1.5: 0.6-3.9) \\
89(1.5: 0.6-4.0) \\
82(1.4: 0.6-3.3) \\
83(2.6: 1.2-5.7) \\
85(1.8: 0.8-4.3) \\
79(1.2: 0.6-2.7) \\
77(2.3: 1.1-4.7)\end{array}$ & $\begin{array}{l}90(2.0: 1.1-3.6) \\
92(2.2: 1.2-4.1) \\
83(1.5: 0.9-2.5) \\
79(2.4: 1.5-3.7) \\
79(1.2: 0.7-1.9) \\
86(2.1: 1.3-3.5) \\
73(1.8: 1.2-2.8)\end{array}$ & $\begin{array}{l}6.6^{\star} \\
7.1^{\star} \\
2.8^{\star \star \star} \\
14.9^{\star \star \star} \\
0.3^{\star \star} \\
9.3^{\star \star} \\
6.9^{\star}\end{array}$ \\
\hline
\end{tabular}

One degree of freedom for all trend tests. ${ }^{\star} \mathrm{p}<0.05, \star \star \mathrm{p}<0.005, \star \star \star \mathrm{p}<0.0005$.

$\mathrm{OR}=$ odds ratios $(\mathrm{OR}=1$ indicates the reference group) $; 95 \% \mathrm{CI}=95 \%$ confidence intervals for odds ratios

(47/62) reported that they stopped for health reasons, $39 \%(22 / 62)$ had partners who objected to their smoking, and another $35 \%$ (20/62) stopped for reasons such as marriage, pregnancy, or loss of enjoyment from smoking.

\section{BELIEFS ABOUT HEALTH RISKS}

The majority of respondents were aware of the most commonly emphasized hazards of smoking, including lung cancer, shorter life expectancy, heart disease, pregnancy complications, shortness of breath, and the risks from passive smoking. The proportion who believed that these consequences applied ranged from $70 \%$ to $90 \%$. However "smoking interactions with oral contraceptives" and "every one in six smokers, who smoke one pack of cigarettes daily, will die from smoking related disease before the age of 65" were outcomes of smoking recognised by only $35 \%$ to $60 \%$ of subjects. In general, there were no significant differences by smoking status in beliefs about the health consequences of smoking except that a higher proportion of current smokers $(48 \%)$ than ex-smokers $(29 \%)$ and neversmokers $(34 \%$ ) believed that smoking can help control body weight (table 3 ).

The respondents' composite knowledge score for the effects of smoking ranged from 0 to 10 , with a mean score of 6.54 (SD 2.62). The composite knowledge score of smoking hazards for current smokers $(\bar{x}=6.83$ (SD 2.07), $95 \%$ CI 6.50-7.16) was not significantly different from that of ex-smokers ( $\bar{x}=6.24$ (SD 2.77), $95 \%$ CI 5.54-6.94) and never-smokers $(\overline{\mathrm{x}}=$
$6.38(\mathrm{SD} 2.63), 95 \% \mathrm{CI} 6.11-6.65)(\mathrm{F}$ ratio $=$ 2.03, $\mathrm{df}=2.585, \mathrm{p}=0.133$ ).

PERCEIVED COSTS AND BENEFITS OF SMOKING Table 4 shows the proportions of ever-smoking and non-smoking respondents' perceptions of smoking consequences if they were to smoke cigarettes daily. A majority of respondents acknowledged an association between regular smoking and the listed negative health con- $\delta$ sequences. In contrast, any benefits of regular smoking were only expected by a relatively 윽 small proportion of cabin crew. Current smokers, more than ex-smokers and neversmokers, emphasized the suggested positive N outcomes of smoking such as greater feelings of relaxation; feeling good; more comfortable in groups; more confident; less bored; and $\mathrm{C}$ believing oneself to be more attractive; more 2 alert, and better able to concentrate. Generally, some responses including feeling good, relaxed, less bored, more alert and better able to concentrate were more emphasized than others. Smokers were three to nine times more likely, and ex-smokers one and a half times more likely, to identify benefits from smoking than never-smokers. Conversely, ex-smokers and non-smokers were up to twice as likely to identify adverse consequences of smoking. Table 5 shows the mean perceived probability that respondents would develop adverse health consequences of smoking if they smoked daily. Current smokers rated this perceived probability significantly lower than did nonsmokers. 
Table 5 Respondents' estimates of the chance (\%) of developing adverse health effects of smoking

\begin{tabular}{|c|c|c|c|c|c|}
\hline \multirow[b]{3}{*}{ Smoking risks } & \multicolumn{5}{|c|}{ Mean estimated chance $\%(95 \% C I)$} \\
\hline & \multirow[b]{2}{*}{ Current smokers } & \multirow[b]{2}{*}{ Ex-smokers } & \multirow[b]{2}{*}{ Never-smokers } & \multicolumn{2}{|c|}{$A N O V A$} \\
\hline & & & & F-ratio & $d f$ \\
\hline $\begin{array}{l}\text { Have lung cancer } \\
\text { Stain fingers/teeth } \\
\text { Shortness of breath } \\
\text { Die at younger age } \\
\text { Addicted to cigarettes } \\
\text { Have heart disease } \\
\text { Impaired taste/smell }\end{array}$ & $\begin{array}{l}55(50-59) \\
64(59-69) \\
59(55-64) \\
51(46-56) \\
68(63-73) \\
56(52-61) \\
56(51-60)\end{array}$ & $\begin{array}{l}67(60-74)^{1} \\
71(63-80) \\
64(56-73) \\
66(58-73)^{1} \\
72(64-80) \\
63(55-71) \\
54(45-63)^{2}\end{array}$ & $\begin{array}{l}68(65-71)^{1} \\
76(73-79)^{1} \\
69(65-72)^{1} \\
68(64-71)^{1} \\
72(68-75)^{1} \\
69(66-73)^{1} \\
67(64-71)^{1}\end{array}$ & $\begin{array}{r}12.7 \\
9.5 \\
5.0 \\
15.5 \\
0.7 \\
10.7 \\
10.2\end{array}$ & $\begin{array}{l}2,558^{\star \star \star} \\
2,558^{\star \star \star} \\
2,555^{\star} \\
2,555^{\star \star \star} \\
2,556 \\
2,559^{\star \star \star} \\
2,559^{\star \star \star}\end{array}$ \\
\hline
\end{tabular}

$\star \mathrm{p}<0.05, \star \star \star \mathrm{p}<0.0005$

Multiple comparison results (Scheffe Test): ${ }^{1}$ significantly different from current smokers at the 0.05 level; ${ }^{2}$ significantly different from never-smokers at the 0.05 level

Table 6 Perceived social images of smoking and non-smoking women

\begin{tabular}{|c|c|c|c|c|c|c|}
\hline \multirow[b]{2}{*}{ Characteristics } & \multicolumn{6}{|c|}{$\%$ of respondents rating } \\
\hline & $\begin{array}{l}\text { Respondents' } \\
\text { smoking } \\
\text { status }\end{array}$ & $\begin{array}{l}\text { Smoking } \\
\text { women as }\end{array}$ & $\begin{array}{l}\text { Non-smoking } \\
\text { women as }\end{array}$ & $\begin{array}{c}\text { Both } \\
\text { smoking E } \\
\text { non-smoking } \\
\text { women as }\end{array}$ & Uncertain & $\chi^{2}$ \\
\hline \multirow[t]{3}{*}{ Feminine } & Current & 1 & 21 & 76 & 2 & $61.4^{\star \star \star}$ \\
\hline & Ex & 3 & 37 & 52 & 8 & \\
\hline & Never & 0 & 53 & 42 & 5 & \\
\hline \multirow{2}{*}{ Attractive } & Current & 1 & 15 & 79 & 5 & $36.7 \star \star \star$ \\
\hline & $\begin{array}{l}\text { Ex } \\
\text { Neyer }\end{array}$ & 3 & 32 & 60 & 5 & \\
\hline \multirow{3}{*}{ Impulsive } & Current & $\begin{array}{r}1 \\
18\end{array}$ & 42 & 52 & 5 & \\
\hline & Ex & 32 & 4 & 61 & 17 & $14.6^{\star}$ \\
\hline & Never & 33 & $\begin{array}{l}2 \\
6\end{array}$ & $\begin{array}{l}49 \\
47\end{array}$ & 17 & \\
\hline \multirow{3}{*}{ Elegant } & Current & 4 & 16 & 74 & 7 & $515^{\star \star \star \star}$ \\
\hline & Ex & 2 & 37 & 55 & 7 & $31.3^{2 x \times x}$ \\
\hline & Never & 2 & 50 & 44 & 4 & \\
\hline \multirow{3}{*}{ Unsophisticated } & Current & 8 & 11 & 64 & 17 & $35.0^{\star \star \star \star}$ \\
\hline & Ex & 20 & 17 & 42 & 20 & \\
\hline & Never & 20 & 26 & 39 & 15 & \\
\hline \multirow[t]{3}{*}{ Fit } & Current & 4 & 48 & 39 & 9 & $23.7^{\star}$ \\
\hline & Ex & 0 & 68 & 22 & 10 & \\
\hline & Never & 3 & 69 & 24 & 5 & \\
\hline \multirow[t]{3}{*}{ Sociable } & Current & 9 & 3 & 84 & 4 & $15.8^{\star}$ \\
\hline & Ex & 2 & 13 & 77 & 8 & \\
\hline & Never & 12 & 9 & 73 & 6 & \\
\hline \multirow[t]{3}{*}{ Adventurous } & Current & 13 & 4 & 74 & 9 & 7.6 \\
\hline & Ex & 22 & 7 & 58 & 13 & \\
\hline & Never & 17 & 8 & 67 & 8 & \\
\hline \multirow[t]{3}{*}{ Free/liberated } & Current & 20 & 4 & 70 & 6 & 2.4 \\
\hline & Ex & 22 & 3 & 67 & 8 & \\
\hline & Never & 24 & 6 & 64 & 7 & \\
\hline \multirow{3}{*}{$\begin{array}{l}\text { Lacking in } \\
\text { confidence }\end{array}$} & Current & 13 & 4 & 59 & 24 & $21.0^{\star \star}$ \\
\hline & Ex & 28 & 3 & 42 & 27 & \\
\hline & Never & 32 & 2 & 46 & 20 & \\
\hline
\end{tabular}

"Current" represents ratings from current smoking respondents

"Ex" represents ratings from former smoking respondents

"Never" represents ratings from never-smoking respondents

Six degrees of freedom for all tests, ${ }^{\star} \mathrm{p}<0.05,{ }^{\star \star} \mathrm{p}<0.005,{ }^{\star \star \star} \mathrm{p}<0.0005$

SOCIAL IMAGES OF SIMOKING

Overall, very few respondents rated smoking women as feminine, attractive, elegant, or fit (table 6). In contrast, these characteristics were attributed to non-smoking women, on average, one and a half to three times as frequently by non-smoking than smoking respondents, with the exception of "fit". Smoking respondents acknowledged nonsmoking women as "fit" compared to smoking women.

Current smoking respondents were significantly more likely to attribute the characteristics of feminine, attractive, and elegant to all women than were ex-smoking and neversmoking respondents. By comparison, smoking women were on average four to five times more likely to be rated as impulsive, adventurous, liberated, and lacking in confidence by all groups of respondents than were non-smoking women. Respondents failed to differentiate smoking from non-smoking women in their attribution of unsophisticated and sociable.
INTERPRETATION OF ADVERTISEMENTS

All three pairs of advertisements were described differently by members of the different smoking groups. With the exception of the alcohol advertisement, the women in nontobacco advertisements were not perceived differently by smoking and non-smoking respondents. In contrast, a higher proportion of current and ex-smoking respondents generally perceived the women in tobacco advertisements more favourably than did never-smoking respondents.

Descriptions of model(s) depicted in the three pairs of advertisements used were as follows:

First pair of advertisements

The women in the advertisement for alcohol were described by more smoking than nonsmoking respondents (smoking status: current vs ex-smokers vs never-smokers) as having the following attributes: 
- feminine $\left(43 \%\right.$ vs $32 \%$ vs $31 \%, \chi^{2}=6.8$, $\mathrm{df}=2, \mathrm{p}=0.033)$

- attractive $\left(60 \%\right.$ vs $55 \%$ vs $47 \%, \chi^{2}=7.4$, $\mathrm{df}=2, \mathrm{p}=0.025)$

- adventurous $\left(27 \%\right.$ vs $10 \%$ vs $26 \%, \chi^{2}=$ $8.3, \mathrm{df}=2, \mathrm{p}=0.016$ )

A higher proportion of smoking than nonsmoking respondents perceived the women in the Kent advertisement as :

- feminine $\left(60 \%\right.$ vs $48 \%$ vs $44 \%, \chi^{2}=10.5$, $\mathrm{df}=2, \mathrm{p}=0.005)$

- attractive $\left(72 \%\right.$ vs $76 \%$ vs $61 \%, \chi^{2}=9.2$, $\mathrm{df}=2, \mathrm{p}=0.010)$

- sociable $\left(91 \%\right.$ vs $82 \%$ vs $81 \%, \chi^{2}=6.8$, $\mathrm{df}=2, \mathrm{p}=0.033)$

- adventurous $\left(38 \%\right.$ vs $19 \%$ vs $32 \%, \chi^{2}=$ $6.7, \mathrm{df}=2, \mathrm{p}=0.036$ )

\section{Second pair of advertisements}

The woman in the cosmetic advertisement was not described in significantly different terms by smoking groups. However, the woman in the Virginia Slims advertisement was described differently by smoking and non-smoking respondents in terms of four attributes. More smoking than non-smoking respondents viewed the woman as attractive, elegant, fit, and sociable (current $v s$ ex-smokers $v s$ neversmokers).

- attractive $\left(77 \%\right.$ vs $67 \%$ vs $58 \%, \chi^{2}=16.3$, $\mathrm{df}=2, \mathrm{p}=0.0003)$

- elegant $\left(62 \%\right.$ vs $51 \%$ vs $41 \%, \chi^{2}=18.9$, $\mathrm{df}=2, \mathrm{p}=0.0001)$

- fit $\left(21 \%\right.$ vs $20 \%$ vs $12 \%, \chi^{2}=7.7, \mathrm{df}=2$, $\mathrm{p}=0.021)$

- sociable $\left(57 \%\right.$ vs $44 \%$ vs $44 \%, \chi^{2}=7.0$, $\mathrm{df}=2, \mathrm{p}=0.031$ )

\section{Third pair of advertisements}

Of the three non-tobacco advertisements, only the woman depicted in the watch advertisement was perceived differently by members of the three smoking status groups as having less desirable attributes. A higher proportion of current smoking than non-smoking correspondents perceived the woman in the watch advertisement as "lacking in confidence", $14 \%$ vs $3 \%$ vs $5 \%: \chi^{2}=14.1, \mathrm{df}=2$ (current vs ex-smokers vs never-smokers).

The woman in the Salem advertisement was perceived as attractive, fit, sociable, and adventurous by more smoking compared to nonsmoking respondents:

- attractive $\left(67 \%\right.$ vs $50 \%$ vs $54 \%, \chi^{2}=8.7$, $\mathrm{df}=2, \mathrm{p}=0.013)$

- fit $\left(39 \%\right.$ vs $26 \%$ vs $28 \%, \chi^{2}=6.5, \mathrm{df}=2$, $\mathrm{p}=0.038$ )

- sociable ( $41 \%$ vs $29 \%$ vs $26 \%, \chi^{2}=11.8$, $\mathrm{df}=2, \mathrm{p}=0.003$ )

- adventurous $\left(54 \%\right.$ vs $40 \%$ vs $40 \%, \chi^{2}=$ $8.5, \mathrm{df}=2, \mathrm{p}=0.014$ )

\section{Discussion}

SMOKING BEHAVIOUR

According to the World Health Organisation (WHO), the incidence of smoking has been increasing most amongst professional and urban women, and it is these groups who therefore face "the greatest and most potent threats to health". ${ }^{7}$ These young professional women usually occupy administrative and managerial positions and most often take up smoking when at college or university. ${ }^{1,7}$ Women who work for multi-national companies, airlines, or the mass media may be more prone to smoking because they are encouraged to emulate their western counterparts in other ways.?

A majority of the smoking cabin crew were light smokers compared with smoking women in western countries. However, the former started smoking for the same reasons as do their western counterparts. The most commonly reported reasons why women start smoking are: 1) curiosity, ${ }^{8-12}$ 2) the influence of family and peer groups, and 3) to establish or maintain a different self-image. The most commonly identified reasons women continue to smoke are: 1) as a reaction to loss of contro over their lives, ${ }^{13,14}$ and 2) as a means of moodcontrol and/or coping with stress. ${ }^{1,15,16}$

\section{REASONS FOR STOPPING SMOKING}

Two of the most frequently mentioned reasons why ex-smokers quit are "health reasons" and "relationship" (pregnancy, objecting boyfriend or spouse). Despite the lack of association between some aspects of health knowledge and smoking behaviour, antismoking programmes should particularly emphasize the health risks of smoking in relation to reproductive health because of the high premium placed on children as a security for old age in Asian communities.

\section{ATTEMPTS TO STOP SMOKING}

The majority of the smokers had attempted to stop smoking at least once. Stopping smoking is not an easy task and women seem to find it especially difficult. ${ }^{1}$ Female smokers in Asia may benefit from information on different smoking cessation methods and more support groups and cessation programmes.

\section{BELIEFS ABOUT HEALTH CONSEQUENCES}

The survey clearly demonstrates that smoking status is not determined by respondents' knowledge of the health consequences of smoking. Maintenance of, and possibly even recruitment to smoking in this group occurred despite declared knowledge of the health risks. Thus, perceived health consequences alone do not suffice as reasons to change behaviour. Peer influence, self-image, and the perceptions of smoking (eg, as a means to control mood) appear to be more salient factors in predicting smoking behaviour. ${ }^{8-16}$

The low level of responses for "interaction with oral contraceptives" and "every one in six smokers, who smoke one pack of cigarettes daily, will die from smoking-related diseases before the age of 65 " indicate that the subjects more readily identify those consequences of smoking which have been most publicised, 
such as "lung cancer" and "shorter life expectancy".

About $40 \%$ of the subjects believed that smoking would help control body weight. This particular group of young women may use smoking to suppress appetite and to keep themselves slim. The nature of their work may make them over-conscious of their appearance and these effects may help to discourage smokers from quitting.

\section{PERCEIVED EFFECTS OF SMOKING}

Overall, smokers generally perceived that the suggested positive results of smoking outweighed the negative health results. This implies that smokers, particularly young smokers, are more likely to focus on more immediate factors than longer term health consequences, as most health problems occur in older age groups and therefore seem distant. Smoking prevention programmes should therefore try to change young people's concept about their vulnerability to the development of smoking-related diseases.

\section{PERCEIVED SOCIAL IMAGES OF SMOKING}

The views held by smokers of the characteristics of women as portrayed in tobacco advertisements may have an important impact on the recruitment of young women smokers. Images representing glamour, adventure, sociability, and youthfulness feature strongly and are emphasized by western models, symbolising greater independence. These images may have a powerful impact on many Asian women who may see themselves as less socially liberated. The social status of women in countries such as Korea, Philippines, Thailand, India, Japan, and Malaysia is still much lower than that of men. This is particularly so for Korean and Indian women. Korean cabin crew had the highest smoking rates in our sample. The smoking rates of Philippino and Thai cabin crew are also high. One reason may be that many of these women smoke to enhance their images of independence. However, South Korea, Japan, and the Philippines were exposed to high levels of western, especially American, influence after World War II, and this may have lead to a greater identification with western female role models.

Most respondents attributed the majority of the characteristics to all women and in general were unwilling to distinguish between smoking and non-smoking women. The exception was "fit", which the majority of respondents attributed solely to non-smoking women. However, it is noteworthy that this attribute was accorded by smokers to the women in the Virginia Slims and Salem advertisements. There are some differences in the responses of smoking and non-smoking respondents, but these only apply to a minority of respondents. Among this minority, two general patterns are discernible. First, non-smoking respondents tended to describe non-smoking women as "feminine", "attractive", and "elegant": what might be considered as traditionally desirable elements of the female gender role. Second, there was a tendency for smoking women to be described by all groups of respondents as "adventurous", "liberated", "impulsive", but "lacking in confidence". While "adventurous" and "liberated" are often perceived as desirable characteristics promoted by smoking advertisements, "impulsive" and "lacking confidence" may be less desirable. Emphasis on these associations might help to undermine the pervasive attempts to portray desirable images of women who smoke. Though these interpretations are for a minority of subjects, they do imply that different perceptions of smoking women exist among some smoking and non-smoking subjects. This is an area that would benefit from further research. It seems likely that smokers made fewer distinctions between the images of smoking and non-smoking women, perhaps to minimise negative associations with their own smoking behaviour and to play down potential differences between the social images of smokers and non-smokers. Similarly the nonsmoking subjects may have sought to enhance their own social image by choosing the positive aspects of not smoking. This could be exploited by anti-smoking workers to minimise any social desirability associated with images of smoking.

\section{VALIDITY AND RELIABILITY}

The under-reporting of smoking prevalence amongst cabin crew raises questions about the validity of responses from employees who are uncertain of their employer's attitude towards smoking. Further research on smoking behaviour should consider ways to avoid or minimise this type of error. Methods such as a brief statement from the participating company emphasising the independent position of the research organisation and the company's supportive views on the study should be explored.

When asked to describe the social images of smoking women, most cabin crew were unwilling to differentiate between smoking and non-smoking women. The distinctions made by the remainder are therefore much weakened. In addition, some cabin crew might not have referred to the definitions provided before responding. Consequently, differing interpretations of the meaning of certain terms may have occurred among subjects. For example, to some subjects "fit" may refer to appearance rather than physical condition. In future research the definition of terms should be juxtaposed with definitive questions and statements, and should limit the choice response to two categories (smoking and non-smoking women) and exclude the category of "all women" to help overcome these problems.

\section{Conclusions}

In this study population, smokers and nonsmokers differed in their perceptions of the utility of smoking and in their estimation of risks from smoking. Smokers reported more 
benefits from smoking and were also more likely to identify with women depicted in tobacco advertisements than were nonsmokers. However, the levels of knowledge of health risks from smoking were similar for both smokers and non-smokers. This suggests that health risks play little part in discouraging smoking among this population. To influence smoking in female cabin crew, we need to focus on changing the perceived benefits of smoking. There is also a need to increase young women's awareness of the subtle influences of tobacco advertising on social image formation.

\section{POSSIBLE INTERVENTIONS}

The results of this study suggest several strategies :

- Increase access to information on means for lifestyle change, including methods for body weight control.

- Establish the teaching of stress management to deal more effectively with occupational and personal stress.

- Emphasise negative social aspects of smoking.

- Promote desirable images of not smoking.

- Reinforce health promotion in the work place.

- Initiate a programme to reduce recruitment to smoking among new cabin crew.

- Establish more smoking cessation courses to help smokers to stop and provide advice and help to smokers during the smoking cessation process.

- Ban all tobacco advertisements which seek to associate glamorous or socially desirable images of women with cigarettes or other tobacco products.

- Initiate further research to clarify the benefits of emphasis on health as a method of analysing smoking behaviour. Where health emphasis occurs, it may be effective to focus on the improvement in female reproductive health to be gained from smoking cessation in addition to respiratory and cardiovascular health, especially for younger age groups.

- Promote non-smoking working environments to help smokers to stop. Since this study began the airline has introduced many non-smoking flights, including some longhaul routes. There is growing concern among cabin crew about the health effects of environmental tobacco smoke in aircraft. A world-wide ban on smoking in passenger aircraft is an important goal for the protection of the health of airline employees.

1 Jacobson B. Beating the ladykillers - women and smoking. London: Pluto Press, 1986.

2 Crofton E. Women and smoking. World Health 1987; 28-30 December.

3 World Health Organisation. Tobacco or Health-Technical Discussions. Geneva: WHO, 1989.

4 Census and Statistics Department. Special Topics - Report No. VII. Hong Kong: Hong Kong Government Publishers, 1990.

5 Editorial. Taiwan: increase in women smokers. South China Morning Post, 13 September 1990, p 12.

6 Respiratory health survey report no 2 , Hong Kong, Department of Community Medicine, The University of partment of Comm

7 World Health Organisation. Press kit for World No-Tobacco Day, 31 May 1989. Geneva: World Health Organisation,

8 Barton J, Chassin L, Presson CC, Sherman SJ. Social image factors as motivators of smoking - initiation in early and middle adolescence. Child Dev 1982; 53: 1499-1511.

9 Dicken C. Sex-role orientation and smoking. Psychol Rep $1982 ; 51: 483-9$

10 Greaves L. The meaning of smoking to women. Proceedings of the Seventh World Conference on Tobacco and Health 1990; 905-7.

11 Swan AV, Melia RJW, Fitzsimons B, Breeze E, Murray M. Why do more girls than boys smoke cigarettes? Health Educ f $1989 ; 48: 56-63$.

12 Charlton A, Blair V. Predicting the onset of smoking in boys and girls. Soc Sci Med 1989; 29: 813-8.

3 Smith GM. Relations between personality and smoking behaviour in pre-adult subjects. $\mathcal{f}$ Consult Clin Psychol 1969; 33: 710-5

14 US Department of Health and Human Services. The health consequences of smoking for women - a report of the Surgeon General, 1980. Washington DC: US Department of Health and Human Services, 1980.

15 Shiffman S. Relapse following smoking cessation: a situational analysis. F Consult Clin Psychol 1981; 50: 71-86.

16 Castro FG, Maddahian E, Newcomb MD, Bentler PM. A multivariate model of the determinants of cigarette smoking adolescents. F Health Soc Behav 1987; 28: 273-89. 